\title{
Psycho-Social Problems of Women Living with HIV/AIDS and its Impact on their Families in Andhra Pradesh, India.
}

\author{
K.Kalpana ${ }^{1}$, Saraswati Raju Iyer ${ }^{2}$ \\ ${ }^{1}$ (Research scholar, Department of Sociology \& Social Work, Acharya Nagarjuna University, A.P,India) \\ ${ }^{2}$ (Asstt. Professor, Department of Sociology \& Social Work, Acharya Nagarjuna University, A.P,India)
}

\begin{abstract}
The global experiences and recent studies reveal that the HIV/AIDS is a life-threatening disease, irrespective of age, gender, cast, creed, colour and race and therefore people react to it in strong ways. Many innocent people have been victimising for this devilish disease without their knowledge. This is very pathetic condition where women have been scapegoats for this disease especially. Instead of getting sympathy and care to these victims from their houses and community, they have been stigmatizing and discriminating by their families and society. Its infection is associated with behaviours (such as homosexuality, drug addiction, prostitution or promiscuity) that are already stigmatized in many societies. Most people become infected with HIV through sex, which often carries a moral baggage. AIDS-related stigma and discrimination refers to prejudice, negative attitudes, ill treatment abuse and maltreatment directed at persons, especially women living with HIV and AIDS. Consequently the stigma and discrimination are being shunned by family, peers and the wider community, poor treatment in healthcare and education settings, an erosion of human rights, psychological pressures, depression and a negative effect on humanity and society as a whole with respect to inter and intra family responses. The effects of antiretroviral therapy on people's physical appearance can result in forced disclosure and discrimination based on appearance in the society in general and in a closed family in particular. So it is essential and crucial to focus on these areas for appropriate approach to bring down the discrimination and empower the victims of HIV/AIDS to lead social life without social stigma. Hence there is at most necessity to study and analyse for an appropriate solution to empower the victims from psychosocial problems posed by their families and society.
\end{abstract}

Key words: discrimination, stigma, psycho-social behaviour, empowerment, victim's family and society.

\section{Introduction}

The AIDS epidemic has had a unique impact on women, which has been exacerbated by their biological vulnerability to HIV infections. Generally women are at a greater risk of heterosexual of HIV. Biologically women are twice more likely to become infected with HIV through unprotected heterosexual intercourse than men. In many countries women are less likely to be able to negotiate condom use and are more likely to be subjected to non-consensual sex. Additionally, millions of women have been indirectly affected by the HIV/AIDS epidemic. Women's childbearing role means that they have to contend with issues such as mother-to-child transmission of HIV. The responsibility of caring for AIDS patients and orphans is also an issue that has greater effect on women. There are number of things that can be done in order to reduce the burden of the epidemic among women. These include promoting and protecting women's human rights, increasing education and awareness among women encouraging the development of new preventative technologies such as post-exposure prophylaxis and microbicides.

While the effects of HIV/AIDS are equally detrimental for all persons affected or infected, certain sections of the population, across the world, however, are more vulnerable in terms of both, contrasting the infection the subsequent consequences. Both structural (psycho-socio) and cultural (traditional norms etc.) factors are responsible for rendering certain sections like women, commercial sex workers, youth, migrants, orphans, children and dependants of family members who are positive, more vulnerable than others.

Women whether, married/single, divorced/widowed, sex workers or seasonal migrants or adolescent girls, are most susceptible to the negative impacts-direct or indirect, i.e. infected or affected, of HIV and AIDS owing to the dynamics between the structural and cultural factors which places them in a weaker and vulnerable position than most others. Further, women are biologically more prone to HIV infections than men in terms of any single act of unprotected sex with an infected partner with the male- to female transmission of the virus being 2 to 4 times higher than the female to male transmission among such sero-discordant couples. The biological structure of women thus also renders more vulnerable than others to HIV and AIDS. Gender disparities in terms of access to education, resources, income, political power, coupled with incidences of sexual violence, coercion, social dislocation in conflict situations like war etc or owing to migration for work, serve to 
the increase the risk of HIV infection to women through unprotected sexual contacts . As a result, women now account for more than half of those living with HIV worldwide and 60\% in sub-Saharan Africa. They constitute one-forth of those infected with HIV in India and one-third in Peru which is indicative of the manner in which gender disparities serve to pose increasing and disproportionate risk to women even in places which have relatively low national prevalence rates. Thus while efforts are being made to curb the spread of the epidemic, there however remain a number of challenges to be addresses and streamlining the policies to the actual trends in the ground is critical. The concerns of gender equity and equality, and women's empowerment in all respects are essential to the prevention, treatment and care in relation to HIV and AIDS. There is an urgent need to strengthen the response towards HIV among women.

\section{Global Scenario Of HIV / AIDS}

As per the latest statistics of UNAIDS on World AIDS Day report 2012, worldwide, women constitute more than half of all people living with HIV/AIDS. Among young people aged 15-24, the HIV prevalence rate for young women twice that of young men. Besides the women in their reproductive years (15-49), HIV/AIDS is the leading cause of death. The statistics of the global HIV and AIDS epidemic were published by UNAIDS, WHO and UNICEF in November 2011, and refer to the end of 2010.

Table: 1

\begin{tabular}{|l|l|l|}
\hline & \multicolumn{1}{|c|}{ Estimate } & \multicolumn{1}{|c|}{ Range } \\
\hline People living with HIV/AIDS in 2010 & 34 million & $31.6-35.2$ million \\
\hline $\begin{array}{l}\text { Proportion of adults living with HIV/AIDS in 2010 who were } \\
\text { women (\%) }\end{array}$ & 50 & $47-53$ \\
\hline Children living with HIV/AIDS in 2010 & 3.4 million & $3.0-3.8$ million \\
\hline People newly infected with HIV in 2010 & 2.7 million & $2.4-2.9$ million \\
\hline Children newly infected with HIV in 2010 & 390,000 & $340,000-450,000$ \\
\hline AIDS deaths in 2010 & 1.8 million & $1.6-1.9$ million \\
\hline
\end{tabular}

Source: Statistics published by UNAIDS in November 2010, referring to the end of 2009.

Table: 2

\begin{tabular}{|l|l|l|}
\hline & \multicolumn{1}{|c|}{ Estimate } & \multicolumn{1}{c|}{ Range } \\
\hline People living with HIV/AIDS in 2009 & 33.3 million & $31.4-35.3$ million \\
\hline Adults living with HIV/AIDS in 2009 & 30.8 million & $29.2-32.6$ million \\
\hline Women living with HIV/AIDS in 2009 & 15.9 million & $14.8-17.2$ million \\
\hline Children living with HIV/AIDS in 2009 & 2.5 million & $1.6-3.4$ million \\
\hline People newly infected with HIV in 2009 & 2.6 million & $2.3-2.8$ million \\
\hline Adults newly infected with HIV in 2009 & 2.2 million & $2.0-2.4$ million \\
\hline AIDS deaths in 2009 & 1.8 million & $1.6-2.1$ million \\
\hline Orphans (0-17) due to AIDS in 2009 & 16.6 million & $14.4-18.8$ million \\
\hline
\end{tabular}

Source: Statistics published by UNAIDS in November 2010, referring to the end of 2009.

The number of people living with HIV rose from around 8 million in 1990 to 34 million by the end of 2010 and proportion of women is in the order of 47 to $53 \%$. By the end of 2009 , there are 15.9 million Women living with HIV/AIDS around the Globe. Where in it was reported in the resent statistics related to 'Asia and the Pacific', nearly 372,000 people became newly infected in 2011, bringing the total number of people living with HIV/AIDS there to nearly 5 million. AIDS claimed an estimated 310,000 lives in the region in 2011.

\section{Indian Scenario}

India has a population of one billion, around half of whom are adults in the sexually active age group. The first AIDS case in India was detected in 1986 and since then HIV infection has been reported in all states and union territories. The spread of HIV in India has been uneven. Although much of India has a low rate of infection, certain places have been more affected than others. HIV epidemics are more severe in the southern half of the country and the far north-east. As per NACO (National AIDS Control Organization Report 2008 GoI ) the highest estimated adult HIV prevalence is found in Manipur (1.40\%), followed by Andhra Pradesh $(0.90 \%)$, Mizoram $(0.81 \%)$, Nagaland $(0.78 \%)$, Karnataka $(0.63 \%)$ and Maharashtra $(0.55 \%)$.In the southern states, HIV is primarily spread through heterosexual contact. Infections in the north-east are mainly found amongst injecting drug users (IDUs) and sex workers.

As per the HIV Estimations 2010, India is estimated to have 23.9 lakh people infected with HIV in 2009 at an estimated adult HIV prevalence of $0.31 \%$. Adult HIV prevalence among men is $0.36 \%$, while among women, it is $0.25 \%$. 
Especially in Andhra Pradesh in the south east part of the country has a total population of around 76 million, of whom 6 million live in and around the city of Hyderabad. Out of 5.1 million estimated cases of HIV/AIDS in India about 10 percent are in Andhra Pradesh. (NACO). This Indian state is home to 76 million people. As per estimates by the National AIDS Control Organisation (NACO), at least 400,000 people infected with HIV reside in Andhra Pradesh. There are 10 districts on high HIV-alert here, which include East Godavari, West Godavari, Krishna, Guntur, Nellore, Prakasam, Karimnagar, caddapah, Nizamabad and Khammam. The situation is likely to get worse as Andhra Pradesh has a vast network of national highways, a vast migrant population, incidents of high traffi cking of girls, strong traditional sexual networks, prevalence of sex with non-regular partners (19 per cent in men and seven per cent in women) and high prevalence of STIs.

Out of the AP's 23 districts, 19 have HIV prevalence of 1 percent of more among ANC women. This is further evidence that HIV is now infecting those in the general population. This movement of HIV out of highrisk groups and into low-risk groups requires continuously expanded efforts to inform and educate the public of the new threat of HIV. For the purpose of this report, district wise prevalence has been estimated using urban and rural data. The number of people found positive for HIV infection at Voluntary Counselling and Testing Centres (VCTCs) provides another indication of the level of HIV in the state. From April 2004 to March 2005, 15.5 percent of those tested state wide were found to be positive. The percentage varied from 4.1 in Krishna district to 26.6 in Guntur. As the Guntur and Krishna neighbouring districts and interaction / mobility levels are very high but the distinct variation in terms of HIV/AIDS cases can be noticed as per statistics.

Table:3

HIV in the General population: Percent of women attending Antenatal Clinics Who tested positive for HIV, Andhra Pradesh, 2005

(Source: APSACS - GoAP)

\begin{tabular}{|c|c|c|c|c|}
\hline S.NO & DISTRICT & URBAN $-\%$ & RURAL - \% & TOTAL \% \\
\hline 1 & West Godavari & 3.25 & 3.00 & 3.14 \\
\hline 2 & Khammam & 3.50 & 2.25 & 2.88 \\
\hline 3 & Prakasham & 2.50 & 3.25 & 2.88 \\
\hline 4 & Guntur & 3.00 & 2.50 & 2.75 \\
\hline 5 & East Godavari & 2.75 & 2.25 & 2.50 \\
\hline 6 & Hyderabad & 2.00 & - & 2.00 \\
\hline 7 & Nalgonda & 2.75 & 1.00 & 1.88 \\
\hline 8 & Krishna & 2.00 & 1.5 & 1.75 \\
\hline 9 & Rangareddy & 1.75 & - & 1.75 \\
\hline 10 & Nizamabad & 0.75 & 2.50 & 1.63 \\
\hline 11 & Vizianagaram & 2.00 & 1.25 & 1.63 \\
\hline 12 & Warangal & 2.50 & 0.75 & 1.63 \\
\hline 13 & Chittoor & 1.25 & 2.00 & 1.50 \\
\hline 14 & Vishakapatnam & 2.5 & 0.50 & 1.48 \\
\hline 15 & Medak & 2.00 & 0.72 & 1.47 \\
\hline 16 & Karemnagar & 2.25 & 0.57 & 1.38 \\
\hline 17 & Adilabad & 1.75 & 1.00 & 1.38 \\
\hline 18 & Anantapur & 1.75 & 1.00 & 1.13 \\
\hline 19 & Nellore & 1.50 & 0.75 & 0.88 \\
\hline 20 & Srikakulam & 1.50 & 0.25 & 0.75 \\
\hline 21 & Karnool & 1.50 & 0.00 & 0.63 \\
\hline 22 & Cuddapah & 0.75 & 0.50 & 0.25 \\
\hline 23 & Mehbubnagar & 0.25 & 0.25 & $\mathrm{An}$ \\
\hline
\end{tabular}

The district wise Percentage of women attending Antenatal Clinics Who tested positive for HIV, in Andhra Pradesh, as per GoAP statistics 2005 shown in table: 3 indicates that the Krishna district has HIV affected women in the order of $2.0 \%$ in Urban areas and $1.5 \%$ in Rural area population.

In Andhra Pradesh the prevalence of HIV among pregnant women had gone down from 1.25 per cent in 2004 to one per cent in 2010. But this was higher than the State average of 0.77 per cent. However, the result of up-scaling of the services was tremendous in the district. Last November, 9,555 PLHIVs (people living with HIV) were receiving ART medicines in Krishna district, compared to the 2,499 PLHIVs who availed the services in January 2008.

The state government has granted pensions to about 35,000 HIV positive patients across the state and the Andhra Pradesh State Aids Control Society (APSACS) has already dispatched ATM cards of the 
beneficiaries to their respective district hospitals. The beneficiaries would receive Rs 200 per month which would be directly deposited to their accounts by APSACS. Confirming the move before a local court at Nandigama.The government had decided to provide financial relief to needy HIV patients. The aids control body had come out with a detailed report in response to a notice issued by the court. The court asked APSACS to submit a report on the measures being taken to assist HIV patients following a petition filed by a HIV patient from Avuthuvari Agraharam village in Jaggaiahpet mandal. The patient alleged that he was denied a concessional bus pass to visit the hospital for anti-retroviral treatment (ART). This scheme was intended for only those living below the poverty line. In addition, APSACS said that concessional bus passes were also being provided to these patients to visit ART centres at least twice in a month. More than 2,500 patients in Krishna district will receive pensions. (Times of India 5/2/12)

\section{Works On HIV/AIDS and Psycho-Social Problems Of Women}

It has become generally recognized that acute and chronic medical conditions in the paediatric population have the potential to bring about a range of psychosocial challenges not only to patients, but also to family members and health care workers. Of these conditions, HIV/AIDS presents perhaps the most complex psychosocial issues of any medical condition. The overlapping of social, individual, family, financial, cultural, and illness factors poses a challenge to communities and healthcare teams that strive to provide comprehensive services to this population.

The existence and rapid spread of HIV and AIDS poses a serious challenge to every nation across the globe. HIV and AIDS have the potential to undermine the massive improvements that have been made in global health over the years. Apart from being a serious health problem, the multi layered effects of the epidemic on the socio-economic fabric of whole nations, makes HIV and AIDS a potential development threat worldwide. The seriousness of the situation and the need to take action has been captured aptly in the

There is an utmost need to address the long-term psycho-social needs of paediatric HIV/AIDS patients in general, women in particular and has been recognized in recent years as it is a critical and crucial, although there is still a little empirical literature regarding the long-term effects of the disease available. There is a need for explicit research to understand psycho-social problems of specific diseases of HIV /AIDS with chronic illnesses in general along with a social stigma in particular and its impact on their families.

Asha Hingar, P. L. Sharma and Vismita Paliwal, (2013), stated that the Human immunodeficiency virus has a large psychological physical and social impact on infected individuals and their families. Stigmatization worsens this impact, it hinders the prevention and treatment of HIV and hampers social support and HIV disclosure. The families most affected by HIV are characterized by low socioeconomic status, which includes such groups as tribal community, drug users, migrants and asylum seekers. Primary and secondary HIV prevention needs to be promoted, which means educating people about HIV, providing materials for its prevention, providing access to treatment and providing programmes that reduce both the short and long term physical, psychological and social harm it causes in adults and children. Specific prevention efforts should be directed at the group of people below 30 years of age.

According to Meenu Sharma, Kalpaz, (2012), The AIDS is undoubtedly the most devastating pandemic mankind has ever faced. As a cure remains elusive, the disease continues to propel the evanescence of life. Today, the global community seems to be struggling as the disease rips apart the social and economic fabric of the society by killing people in prime of their youth, rendering millions of children orphans and shattering homes and hopes alike. With remote prospects for a cure/vaccine, the challenge to contain the spread of HIV has become imperative. Although no culture or community is known to be immune to AIDS yet, certain populations are more vulnerable to the disease because of their high-risk behaviours. Also, it is true that certain vulnerable populations have remained either untouched or non-responsive to the ongoing prevention efforts. The book delves into the lives of some such communities with a modest attempt to create AIDS awareness amongst them. It focuses on documenting high-risk behaviour as well as in delineating factors fuelling them. A concerted effort has been made to understand various issues that can effect desirable behavioural changes in context to HIV/AIDS. The endeavour also envisages to demonstrate how community participation can be effectively used in raising HIV/AIDS awareness as well as in achieving sustainability of the programme. What follows henceforth is a significant transition leading from a state of unawareness to awareness

Jai P Narain (2012), described that a work by health and development experts and professionals, this wellresearched compilation traces the evolving and highly dynamic nature of HIV/AIDS and its unprecedented health and development threat in Asia. Three decades of HIV/AIDS in Asia studies how the region has responded to this epidemic in the last three decades. It contains country-specific chapters on the HIV/AIDS problem-low-prevalence countries such as Bangladesh and Sri Lanka as well as countries with advanced epidemics such as Cambodia, China, India, Pakistan, Thailand and Vietnam-and the evolving response to it. There is recognition of the fact that Asia remains the hardest hit after Africa. The lesson learnt from the Asian countries show that HIV can be prevented and clinically managed with sustained political commitment, 
adequate human and financial resources, and inter-sectoral action. With the modus operandi of real-life stories and case studies, this work is highly relevant in assessing the ground reality and the measures required for effective prevention, treatment, and care across the continuum.

Ram Shankar Singh and Sunil Kumar,(2011), indicated that the most important way to change risky behaviour is health education. Several studies have shown the positive impact of education and health literacy on cautious sex behaviour. Education itself does not work, only it leads to higher health literacy and general cognitive ability. It creates choices and opportunities for people, reduces the twin burdens of poverty ad diseases and gives a stronger voice in society. Ram Shankar Singh and Sunil Kumar (2011), in their study it was emphasised that There is currently no publicly available vaccine for HIV or cure for HIV or AIDS. The only known methods of prevention are based on avoiding exposure to the virus or failing that an antiretroviral treatment directly after a highly significant exposure called Post Exposure Prophylaxis PEP. It was emphasised that it can educate the policy makers', consultants', teachers', researchers, NGOs managers and administrators for the total welfare of humanity. It can serve to add knowledge to students gynaecologists paediatricians behavioural scientists social workers health educators home scientists managers and other faculty members for prevention of diseases and promotion of health. Shaila Parveen (2010), discussed the HIV/AIDS pandemic is entering a new more dangerous phase. As the global threat increase, there are many sign of growing complacency persistence denial and resurgent discrimination. A creative revitalization of effort against AIDS is needed. It was to bring together current knowledge of HIV/AIDS, it explores the complexities of the issue challenges thrown up by the contemporary situation in India. This is the outcome of the conclusion of a study of about 300 social work students from different universities; the basic objective is to evaluate the knowledge and attitude towards HIV/AIDS. Besides, it also offers examples of government action that has been taken to combat this disease. The generalization made on the basis of response of the present study will prove helpful to the researchers, social work students, nursing students, policy makers who are interested in concerned with further studies about the status of HIV/AIDS.

Akash Gulalia, G.V.L. Narsimha Rao and Sanjay Bhatt, etal., (2010), pointed out that it is an outcome of several qualitative and quantitative studies conducted to understand patterns of migration and HIV risk in India. It is an edited version of the research report funded and presented to Department of International Development India for the purpose of assessing and exploring the subject for the purpose of policy formulation. The research was conducted by Development Research Services Pvt. Ltd and authors conducted study supported by a team of experts and research specialists. The book provides an insight on the issue of migration, mobility and HIV risk in India. With its unique blend of qualitative and quantitative research methodology and framework, this book will be of immense value to diverse audience which include public health professionals, social workers, NGOs, researchers, policy makers and educators involved in prevention and rehabilitation of drug addicts.S. Sakthi (2010), stated that this research endeavour has been undertaken among women living with HIV Positive in Chennai City of Tamil Nadu, with the objectives of investigating the socio-economic background, marital status, circumstances leading to HIV infection, sexual behaviour after infection, impact of HIV/AIDS in social relationships and their attitude towards pregnancy and child birth after infection. Since the prevalence of HIV is an estimated figure based on sentinel surveillance data on the selected sites according to UNAIDS/WHO criteria, the universe is not taken into consideration for this study. Therefore, purposive sampling technique is adopted to contact the respondents by resorting to snowballing procedure. Accordingly, 200 women living with HIV positive in Chennai city were interviewed with the structured interview schedule to collect required information on the line of objectives formulated for the study. Apart from interview with the respondents, discussion was also held with Government officials and N.G.Os working in AIDS intervention programmes. Available data had been subjected to process statistically leading to analysis and interpretation. Based upon the analysis and findings, a specific action plan has been evolved to provide care and support for the women infected with HIV and to create AIDS free society." According to Random House India, (2008), under the title of 'Untold Stories of India' covering sixteen stories, sixteen lives in India is already home to 5.2 million HIV cases-outnumbered only by South Africa. But AIDS is still a disease stigmatised and shrouded in denial. In this unique anthology, sixteen of India's best known writers go on the road to uncover the country's AIDS epidemic: the trucker who makes his punishing all night journeys; the disaffected youth in the Northeast, many of whom are now injecting drug users; and the housewives who have unknowingly contracted the disease from their husbands. William Dalrymple meets the devadasis, many of whom have become victims of HIV; Kiran Desai goes to meet the coveted sex workers of coastal Andhra; Sunil Ganguly returns to his old haunt, Sonagachhi; Salman Rushdie spends a day with the hijras of Bombay; Sonia Faleiro looks at the destructive nexus between the police and sex workers; and Shobhaa De writes about when AIDS came home. Together the pieces make up a complex - and gripping - picture of AIDS in India: who it's affecting, how and why. UNICEF (2008) evaluated that the assessment is the result of a collaborative effort of many organizations, agencies and individuals working to improve the situation of children and women affected by HIV and are vulnerable to HIV infection in Bangladesh. The successful completion of the assessment was possible with support from 
the staff of the NGOs other organizations/agencies that facilitated the work of researchers. They participated directly or indirectly in the preparation, implementation of the study and finalization of the report. People living with HIV generously shared their experience with the researchers which added pragmatic value to this assessment."

Radhika Ramasubban and Bhanwar Rishyasringa, Rawat, (2005), declared about the AIDS stigma exists around the world in a variety of ways, including ostracism, rejection discrimination and avoidance of HIV infected people, compulsory HIV testing without prior consent or protection of confidentiality, violence against HIV infected individuals or people who are perceived to be infected with HIV and the quarantine of HIV infected individuals. Stigma-related violence or the fear of violence prevents many people from seeking HIV testing, returning for their results, for securing treatment, possibly turning what could be a manageable chronic illness into a death sentence and perpetuating the spread of HIV. 'AIDS Research and Control Centre' (ARCON), Mumbai, pointed out the major findings include that majority of the patients are migrants of rural areas, from low-income group, less educated, depressed and have lost their hopes for future. It was observed that most patients have the fear of being abandoned from their family if they reveal their HIV status. The economic problems are the major issue, because managing money for the long-term treatment is difficult for those who can hardly afford for their sustenance. In case of the females, majority has been infected husbands are living alone. Women were at a disadvantage with their in-laws and there is definitely the danger of abuse. So it essential and crucial to focus areas related to assess the psycho-social problems of women living with HIV/AIDS and to understand the impact of psycho-social problems of the victims on their families as inadequate considerations have been noticed which is the essential part for successful implementation of any programme.

\section{Social Vaccination And Discussion}

Most of the studies express the problems and concerns related to the people who are living with HIV \& AIDS and valuable suggestions have been presented in different directions of the entire spectrum. Only a very few studies are convey the social, economical and emotional feelings of the women living with HIV \& AIDS to the society. It is essential to understand comprehensively with a set focus in the society and among the family members of the victims about the infected women and their mental condition. So through this research the author proposed to investigate and to explore the feelings of the infected women regarding stigma \& discrimination and emotional factors which are compelling them to death some times. The research hypothesis is a predictive statement that relates to independent variable to a dependent variable. A few observations and understanding based on the objectives, broad reasons related psycho-social problems leads to focus the following:

- Illiteracy can be one of the main reason for HIV/AIDS.

- Sexual contact can be another main reason to get affected by HIV/AIDS.

- Extramarital relationship can be one of the major problems.

- Unprotected sexual contact with someone who has HIV.

- Stigma \& discrimination towards the infected women in community is high.

- Poverty leading to 'Transactional Sex' can be reason for acquiring HIV/AIDS.

- Blood transfusion is a major risk for HIV/AIDS.

- Sharing contaminated needles and syringes can cause AIDS.

- Low social status can be one of the reasons for acquiring AIDS.

- Level of understanding the emotional factors of the infected women is insignificant in the family.

- Most women may be infected by their husbands as husbands education and awareness is limited in this area.

- Migration of men from rural to urban can increase the possibility of transmitting HIV/AIDS to their rural women.

- Family breakdown or lack of connectedness can be the reason for acquiring HIV/AIDS.

- Supporting level of NGOs and Govt. to the infected women is not adequate especially counselling to the family is hardly covered in their programme.

- Implementation mechanism of GoI programmes reaching to beneficiary is less effective, though the statistics show recognisable improvement in the status and there is a possibility of ignoring sensitive details of stigma and discrimination.

- Programmes related to stigma \& discrimination is not adequate as stages wise behavioural changes and related responses of the family and society.

- High way prostitution in terms of transporters to be considered especially in motels and dark areas of the highway.

- Informal sectors of low economic groups may vulnerable victims for the desease and transmitting the same to other. 


\section{Impact Assessment}

HIV/AIDS affects the inter / intra social relations in society, economic well-being of families, businesses, and societies in many ways. When people become ill and die, society loses not only those people but also their productive potential. They no longer hold jobs, manufacture goods, provide services, or domestic work to support their families. Families lose their support; the nation loses people who contribute to the wellbeing of society. As families use their time and money to care for ill members, their energies are diverted from working to provide income or farming to provide food. Not only the present but also the future is affected, as family members discontinue education because of the financial needs of the family. The complexities of multi dimensional parameters have to be investigated to derive appropriate and pragmatic measures on the basis of the above observations.

\section{Conclusions}

Health care professionals who have lost many patients to HIV/AIDS begin to suffer because they have inadequate time to grieve or deal with their losses. Like their patients, they display many of the symptoms of the stages of grief (denial, anger, guilt, bargaining, depression, and acceptance). However, as they experience loss after loss, the stages become intermingled. They have not worked through one loss before another occurs. Loss of multiple patients can lead to complicated and ongoing grief and can prevent the health care worker from processing the thoughts, feelings, and responses to patients in healthful and helpful ways. Over time, the unacknowledged sadness, anger, and guilt can become compressed and result in cynicism and decreased ability to invest emotionally in patients. It is painful to acknowledge the feelings associated with seeing patients suffer and die, so the professional becomes more hardened and expresses less sensitivity and sympathy for the needs of the next patient. Discrimination against people with HIV may occur at all levels of the community, including to and from health workers. Almost invariably, such discrimination is the result of a lack of education about HIV/AIDS or misperceptions that are also common in the wider community. It is apparent that health workers, as members of local communities, may have some of the same community negative attitudes and beliefs until appropriate education and role modelling by senior colleagues and peers occurs. However, after appropriate training, it is apparent that health workers' views and practices and the health climate regarding HIV/AIDS can change significantly. This change is important from a human rights perspective because ill people have a right to nonjudgmental and professional treatment. So as per Impact assessment, analysis and its interpretation may lead to identify indicators so as to recognise it as tools to work out appropriate recommendations and to draw conclusions.

\section{Acknowledgements}

The Author acknowledge the professor, Dr. Srikonda Ramesh, School of Planning and Architecture, Vijayawada, Established by MHRD, GoI, for data and guidance given in the social vaccination and other aspects to HIV/AIDS victims of women.

\section{References}

[1] Ahmad, Shekh Belal., 'HIV/AIDS Patients and their Rehabilitation', Serials Publications, 115 p, (ISBN: 9788183875479 ), 2012.

[2] Beyrer $\mathrm{C}$ et al. Modeling men who have sex with men: populations, HIV transmission, and intervention impact. In: Policy and human rights: the global HIV epidemics among men who have sex with men, 2011. Washington, DC, World Bank, 2011.

[3] Cook C,(2010), 'The global state of harm reduction 2010: key issues for broadening the response'., London, Harm Reduction International,2010.

[4] 'Global HIV/AIDS Response: Epidemic update and health sector progress towards Universal Access 2011'.

[5] Gulalia, Akash., Rao, G.V.L.N \& Bhatt, S ., 'Patterns of Mobility, Migration and HIV Risk in India', Mohit Publications, 2010, viii, 338 p, (ISBN : 9788174455062 ),2010.

[6] Hingar, Asha., Sharma, P L. \& Paliwal, Vismita. 'HIV/AIDS : Health Family and Community' Ritu Publications, 188 p, tables, (ISBN : 9789381422724),2013.

[7] Human Rights Watch (2011) 'World Report 2011: Events of 2010'

[8] India.gov.in, 'Spotlight: National Portal of India National AIDS Control Programme', accessed 13.07.2010

[9] Indrani Gupta, Mayur Trivedi and Subodh Kandamuthan, 'Adoption of Health Technologies in India : Implications for the AIDS Vaccine' : Sage, 2007, pbk, 236 p, tables, figs, ISBN : 8178297392,2007

[10] Jai P Narain, Jai P., 'Three Decades of HIV/AIDS in Asia', Sage, 2012, 468 p, (ISBN : 9788132109075),2012.

[11] Kalpaz, M.S., 'AIDS Awareness Through Community Participation : An Action Research', Reprint, 366 p, (ISBN : $8178354713), 2012$.

[12] NACO (2010, July) 'Red Ribbon Express': National AIDS Control Programme, Phase-III, India.

[13] Parveen,shaila., 'HIV/AIDS : Problems and Attitude', Manak Pub, , xvi, 268 p, (ISBN : 9788178312408), 2010.

[14] Random House India ,'AIDS Sutra: Untold Stories from India', Hardback, 352 p, 1, (ISBN : 9788184000399), 2008.

[15] Sakthi, S . 'Plight of HIV Infected Women: Plan of Action for Prevention and Control', Discovery Pub, 2010 , xiv, 318 p, (ISBN : 818356635),2010.

[16] Singh, R.S \& Kumar,S. 'Treatment and Prevention of HIV/AIDS', ABD Pub, 2011, viii, 296 p, (ISBN : 8183762656),2011.

[17] Singh, R.S \& Kumar,S. 'AIDS and Civil Society’ ABD Pub, viii, 320 p, (ISBN : 9788183762670$), 2011$.

[18] Suri, Shalini., 'AIDS : Causes Prevention and Treatment', APH, 2012, vii, 282 p, (ISBN : 81313130390,2011. 
[19] Sharma, Sheel., Atero ,Angella Atwaru 'Empowering Women Through Better Healthcare and Nutrition in Developing Countries', Regency Publications, 2012, xv, 325 p, (ISBN : 9788189233754), 2012.

[20] The Hindu (2nd December 2008) 'The Red Ribbon Express chugs its way back home'

[21] The Times of India (2012, 12th January) 'HIV 10 times more prevalent among migrants than general population'

[22] UNICEF 2008, 'Assessment of Risk and Vulnerability of Children and Women to HIV in Bangladesh', 2008.

[23] UNAIDS (2010) 'UNAIDS report on the global AIDS epidemic'

[24] UNAIDS (2011) 'UNAIDS World AIDS Day Report 2011'.

[25] UNAIDS/WHO Working Group on Global HIV and STI Surveillance. Guidelines on surveillance among populations most at risk for HIV. Geneva, World Health Organization, 2011.

[26] UNGASS (2010, March 31st) 'India - Country Progress Report'

[27] WHO (2010),conference proceedings 'Guidance for the prevention and treatment of HIV and other sexually transmitted infections among men who have sex with men and transgender people', Geneva, World Health Organization, 2010. 